\title{
A Phonological Analysis of Passive Structures in Kisukuma
}

\author{
Muteb A. Alqarni \\ King Khalid University, Saudi Arabia
}

\begin{abstract}
The current paper documents and examines the passive structure in Kisukuma, a Bantu language spoken in Tanzania. It provides a phonological analysis of the marker [-w-] as opposed to its variants, i.e. [-iw-] and its absence [- $\emptyset-]$. The documented data is accounted for according to the principles of Chomsky and Halle (1968)'s rule-based derivational theory. In this paper, I show that Kisukuma does not allow three occurrences: (i) diphthong formation, (ii) gemination, and (iii) [+labial $]^{\wedge}[+$ labial] combination. Although Chomsky and Halle (1968)'s rule-based derivational theory provides an accurate account for all the data, it fails to explain why the [+labial] sound, [-w-], is sometimes deleted, and it is in other times retained yet the final [+labial] consonant of the stem undergoes deletion instead.
\end{abstract}

Index Terms-passive, kisukuma, phonology, Bantu languages

\section{INTRODUCTION}

Although the analogy between passive morphemes in Bantu languages can be clearly noticed through the most prevalent extension, -(ib)w-/ -(ig)w, Bantu languages may be relatively different in terms of the extent to which they allow the usage of passive (Fleisch, 2005, p. 2). Certain forms of passive, for instance, are attached to even intransitive verbs, or verbs which do not assign an agent role. So, it is worth mentioning that passive construction in Bantu languages, albeit their relative morphological resemblances, diverges from language to language in terms of their morphology and function.

According to Ethnologue language of the world, Kisukuma is a Bantu language in Tanzania, spoken by around 5.4 million native speakers in Shinyanga, Mwanza, Kagera, Tabora, Singida, Kigoma and Mara regions and between Lake Victoria and Lake Rukwa, to Serengeti plain.

Kisukuma structure is rich in agglutinative verb morphology. Syntactic or semantic relations can be understood through the attachment of morphemes with relatively constant forms. Each morpheme is attached to the right/left neighboring morpheme, and occupies a fairly fixed position within the verbal phrase. This can be illustrated below through the verbal structure paradigm of the word a-ga-n-inh-il-w-a 'was given for' in Table (I) below:

TABLE I

THE MORPHEMES OF A-GA-N-INH-IL-W-A 'WAS GIVEN FOR'

\begin{tabular}{|c|c|c|c|c|c|c|}
\hline $\mathbf{a}$ & -ga- & -n- & -inh- & -il- & -W- & $-\mathbf{a}$ \\
\hline $\begin{array}{l}\text { Subject-agreement } \\
\text { morpheme with the } \\
\text { function of creating an } \\
\text { agreement between the } \\
\text { verb and the noun phrase } \\
\text { in the subject relation. }\end{array}$ & $\begin{array}{l}\text { Tense- } \\
\text { aspect } \\
\text { marker }\end{array}$ & $\begin{array}{l}\text { Object agreement } \\
\text { morpheme with the } \\
\text { function of creating an } \\
\text { agreement between the } \\
\text { verb and the noun phrase } \\
\text { in the object relation }\end{array}$ & $\begin{array}{l}\text { Verb } \\
\text { Stem }\end{array}$ & $\begin{array}{l}\text { Applicative } \\
\text { markers: } \\
\text { Instrumental } \\
\text { Benefactive } \\
\text { Locative }\end{array}$ & $\begin{array}{l}\text { Passive } \\
\text { marker }\end{array}$ & $\begin{array}{l}\text { Final } \\
\text { Vowel }\end{array}$ \\
\hline
\end{tabular}

The aim of this paper is to document the passive structure in Kisukuma and give an accurate account for their phonological alternations. The paper is divided as follows. Section (II) presents the data and investigates the preliminary difficulties thereof. Section (III) analyzes the data thoroughly. Concluding remarks are given in section (IV).

\section{Phonology of PASSIVE}

Consider the following data, collected from a native speaker of Kisukuma during the author's stay (2011-2014) at University of Florida: 


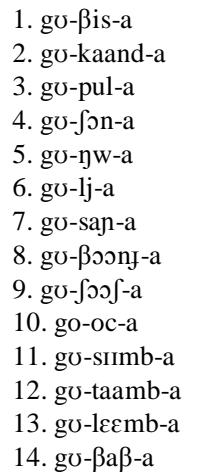

\begin{tabular}{|c|c|}
\hline 'to hide' & go- $\beta$ is-w-a \\
\hline 'to touch' & go-kaand-w-a \\
\hline 'to snatch' & go-pul-w-a \\
\hline 'to weave' & gu- $\int o n-w-a$ \\
\hline 'to drink' & go-nw-iw-a \\
\hline 'to eat' & go-1-iw-a \\
\hline 'to praise' & go-saj-iw-a \\
\hline 'to taste' & go-ßoon」-iw-a \\
\hline 'to answer' & go-foof-iw-a \\
\hline 'to roast' & go-oc-iw-a \\
\hline 'to dig' & gu-sIImv-a \\
\hline 'to sacrifice' & gu-taamv-a \\
\hline 'to deceive' & 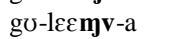 \\
\hline 'to kill by fire' & $g u-\beta a-w-a$ \\
\hline
\end{tabular}

\author{
'to be hidden' \\ 'to be touched' \\ 'to be snatched' \\ 'to be woven' \\ 'to be drunk' \\ 'to be eaten' \\ 'to be praised' \\ 'to be tasted' \\ 'to be answered' \\ 'to be roasted' \\ 'to be dug' \\ 'to be sacrificed' \\ 'to be deceived' \\ 'to be killed by fire'
}

In the examples above, the variants of the passive maker in Kisukuma are [-w-], [-iw-], and [- $\varnothing-]$. The passive marker [-w-] is attested in (1) through (4) plus example (14) that differs from (1) through (4) in that the sound before [w-] is a vowel not a consonant. As for the examples (5) through (10), the marker is [-iw-]. The examples (11) through (13) show no trace for passive marker [- $\varnothing-]$ other than the phonological alternation of [mb] into [mv].

In this paper, I attempt to provide a unified phonological account for all these variants. I will hypothesize that the morpheme /-u-/ is the underlying form which all other allomorphs appear.

Prior discussing this hypothesis, a note should be given regarding the phonological processes that occur in the data above. There is a consensus that the underlying form of the glide [-w-] in the passive markers ([-w-] or [-iw-]) undergoes a glide formation process (i.e. glidization). Glidization is well-attested in Kisukuma. Consider the following examples from Matondo (2006).

15. lia $\rightarrow$ lya 'eat'

16. kua $\rightarrow$ kwa 'pay dowry'

In the examples (15) and (16), it is apparent that Kisukuma does not allow diphthongs /ia/ or /ua/. Thus, /i/ and /u/ change into their respective glides /j/ or /w/. Since the passive /u/ makes a diphthong with the final vowel /a/ (i.e. becomes /ua/), /u/ get glidized as -w- in (1) through (10), plus example (14). Thus, we can formulate this change as a rule in (17).
17. $\mathrm{u} \rightarrow \mathrm{w} /$ $+\mathrm{V}$
$\mathrm{V}=$ Vowel

Another complexity follows from the fact that the morpheme [-iw-] in (5) through (10) appears after stems ending in /w, $1, \int, \mathrm{c}, \mathrm{n}$, and $\mathrm{J} /$. These consonants $/ \mathrm{w}, \mathrm{l}, \int, \mathrm{c}, \mathrm{n}$, and $\mathrm{J} / \mathrm{cannot}$ be all grouped under one natural class. Although $/ \int, \mathrm{c}, \mathrm{n}$, and $\mathrm{J} /$ in (7) through (10) are (alveo)-palatal, /w, $\mathrm{l} / \mathrm{in}(5)$ and (6) cannot be grouped along with them, neither can be grouped under a separate natural class. This casts doubts whether [-w-] is the passive marker yet the vowel [i] is inserted for certain phonological reasons, or the full marker [-iw-] is the passive marker, yet the [i] is deleted in the other examples.

Another complexity arises in the examples (3) and (6). The passive forms of the examples (3) and (6) are stems ending in $/ 1 /$, yet the passive is [-w-] in (3) and [-iw-] in (6). Whether the passive marker is [-iw-] or [-w-], what motivates the [i]-insertion or [i]-deletion, if any, in (3) and (6)? (see discussion in section III).

In (11) through (13), there exists no marker for passive other than this phonological change of [mb] into [mv]. This change requires two phonological processes in a strict order: (a) spirantization and (b) dentalization. Spirantization is a phonological process where [b] changes into [v]. Secondly, dentalization (or place assimilation) is a process where [m] changes into the labio-dental nasal $[\mathrm{m}]$ before the labio-dental fricative [v]. Without spirantization ([b] $\rightarrow[\mathrm{v}])$ occurring first, $[\mathrm{m}]$ will not change into the labio-dental $[\mathrm{m}]$ because of the absence of labio-dental [v]. The two rules are summarized below.
18. $\mathrm{b} \rightarrow \mathrm{v} / \ldots+\mathrm{u}$
19. [nasal] $\rightarrow[\alpha$ place $] /$ [ $\alpha$ place $]$
(Spirantization)
(Dentalization)

For now, I will assume that the marker in (11) through (13) is [- Ø-], but I will revise this in section III. Finally, example (14) shows a deletion process where $[\beta]$ gets deleted before the marker [-w-]. I will formulate this process as in (20).
20. $\beta \rightarrow \varnothing /$ $+\mathrm{W}$
(Deletion)

To summarize, I propose that the underling form of the passive marker is /-u/ which is however glidized as [-w- $]$ to prevent the formation of the diphthong [u+a] which is illegitimate in Kisukuma. I show that the passive marker [-iw-] appears before /w, $1, \int, \mathrm{c}, \mathrm{n}$, and $\mathrm{J} /$ that cannot be naturally classified. With the absence of the passive marker, I point out that $[\mathrm{mb}]$ changes into $[\mathrm{mv}]$ due to (a) spirantization and then (b) dentalization. Finally, I show that [ $\beta$ ] is deletd before [-w-] as attested in (14).

In the following section, I will motivate the hypothesis that the underlying marker is /-u-/ and will account for the already presented complexities.

\section{ANALYSis OF KISUKUMA PASSIVE MARKER}


In this paper, I propose that the marker [-w-] is the passive marker of Kisukuma because it occurs elsewhere. For the following repeated data, I propose that the marker is still [-w-] yet a front high vowel [i] is inserted before [-w-].

\begin{tabular}{|c|c|c|c|}
\hline 21. go-nw-a & 'to drink' & go-nw-iw-a & 'to be drunk' \\
\hline 22. go-lj-a & 'to eat' & go-l-iw-a & 'to be eaten' \\
\hline 23. gu-saj-a & 'to praise' & go-sap-iw-a & 'to be praised' \\
\hline 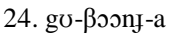 & 'to taste' & 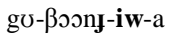 & 'to be tasted' \\
\hline 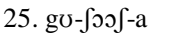 & 'to answer' & gu- $\int \partial 0 \int-i w-a$ & 'to be answered' \\
\hline 26. go-oc-a & 'to roast' & go-oc-iw-a & 'to be roasted' \\
\hline
\end{tabular}

Considering the examples (23) to (26), it is obvious that [i] is inserted after alveo-palatal sounds / $/ \mathrm{c}, \mathrm{n}$, and $\mathrm{J} /$. Rather than using a generic feature [+palatal], I use more specific features such as [+coronal -anterior +distributed] that group all the given sounds above as shown in (27).

$27 . \varnothing \rightarrow[\mathrm{i}] /[$ + coronal - anterior +distributed $] \ldots$ w $+\mathrm{FV} \quad \mathrm{FV}=$ final vowel

Thus the derivation of the representative example (24) will be as in (28).

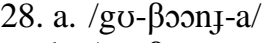

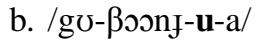
Underlying Form
c. /gu- $\beta$ oonj-w-a/
Insertion of Passive /u/

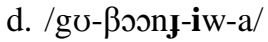
Glidization rule (17)
[i]-Insertion rule (27)

First, the passive marker /-u-/ is inserted and glidized as [-w-]. Then, [i]-insertion rule is triggered due to the presence of the final sound in the stem [J] which is [+coronal -anterior +distributed].

If this is the case for all these examples, what is left to be accounted for is the appearance of [-iw-] in examples (21) and (22) repeated below:
39. gø-yw-a
'to drink'
30. go-1j-a
'to eat'
go-nw-iw-a
go-l-iw-a
'to be drunk'
'to be eaten'

For (29) and (30), the sounds /w/ and /1/ cannot be naturally classified with the earlier sounds, neither do they both constitute a separate natural class. I will propose that the nature of [i] in these examples is different and needs separate motivation. This will explain these problematic data.

For (29), my informant observes that geminate sounds are not legitimate in Kisukuma at all (personal communication). Thus, I propose that the insertion of the vowel [i] is driven to correct the violation of gemination as in (31).
31. $\varnothing \rightarrow[\mathrm{i}] / \mathrm{C}_{1} \_\mathrm{C}_{2}$
where $\mathrm{C}_{1}=\mathrm{C}_{2}$

Thus, the derivation for example (29) will be as in (32).
32. a. /gv-nu-u-a/
Underlying Form
b. /gu-nw-u-a/
Glidization
c. /gu-nw-w-a/
Glidization
d. /gu-nw-iw-a/
/i/-insertion (31)
e. [gu-nw-iw-a]
Surface Form

Now let us turn to the second example (30) repeated below as (33).

$$
\text { 33. gu-lj-a 'to eat' go-l-iw-a 'to be eaten' }
$$

For example (33), I propose that the [i] in the passive form is not inserted, yet it is part of the underlying form of the stem, i.e. /gu-li-u-a/. Consider the active form [go-lj-a]. The sound [j] is part of the stem [lj]. However, the stem [lj] has the underlying form /li/. Yet, the /i/ vowel in the active underlying form /go-li-a/ is glidized as /j/ to prevent the formation of diphthongs, yielding /gv-lj-a/ 'to eat'. Thus, I propose that the underlying passive form in (33) is /gu-li-ua/ (notice that /i/ is part of the stem). Later on, the passive marker /-u-/ is glidized as [-w-] to yield the form /gu-l-iw-a/ 'to be eaten'.

This solution will be better than the alternative hypothesis that / $\mathrm{j} /$ in the active form /go-lj-a/ is deleted in the passive form /gv-l-u-a/ and then [i] is inserted after /1/. This hypothesis has three downsides: first, what motivates the deletion of [j] from the stem? Second, /l/ is not an alveo-palatal sound, so what motivates the insertion of [i]? Third, if we consider the example (3) repeated below as (34), we can confirm that [i] does not need to be inserted after /1/ in the data.

$$
\text { 34. go-pul-a 'to snatch' go-pul-w-a 'to be snatched' }
$$

Let us now turn to the final instances where the passive marker [-w-] is deleted.

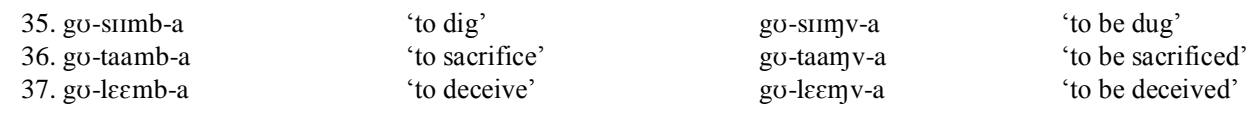


Earlier, I propose that the passive marker in the above data is [- $\varnothing-]$. In this analysis, however, I maintain that the passive marker in the examples above is still /-u-/ which plays a role in the formation of the passive voice, but is eventually deleted. The marker/-u-/ will be important in triggering spirantization.

Spirantization ([b] $\rightarrow[\mathrm{v}]$ ) is mostly triggered by a high vowel (Bhat, 1978; Pulleyblank, 2006). For example, spirantization occurs before /i/ in Awa but before /i, $\mathrm{u} /$ in Lower Grand Valley (Bhat, 1978). Given that the passive marker is a high vowel /-u-/, I propose that it is behind the spirantization process ([b] $\rightarrow$ [v]). The glide formation (/u/ $\rightarrow / \mathrm{w} /$ ) occurs after spirantization takes place. Afterwards, dentalization $(/ \mathrm{m} / \rightarrow / \mathrm{m} /)$ occurs due to the impact of the labio-dental /v/. After all these processes take place, /w/ is deleted as shown in the derivation of example (36).
38. a. /gu-taamb-u-a/
b. /gv-taamv-u-a/
c. /go-taamv-w-a/
Underlying Form
d. /g $\delta$-taamv-w-a/
Spirantization
e. /go-taamv-a/
f. [go-taamv-w-a]
Glidization
Dentalization
/w/-Deletion
Surface Form

It should be noted that Spirantization should precede Glidization, otherwise the spirantization process will be blocked given the change of $(/ \mathrm{u} / \rightarrow[\mathrm{w}])$. However, the order of Glidization and Dentalization is unrestricted.

Now, the question is why [-w-] is deleted. My informant notices that a labial sound cannot be followed by another labial sound in Kisukuma (personal communication). Since [w] and [v] are both [+labial], the passive marker [w] is deleted. I will formulate the [w]-deletion rule as follows.
39. /w/ $\rightarrow \varnothing /$ [+labial] FV
$(\mathrm{FV}=$ final vowel, /a/)

I have evidence that this is true across the board in Kisukuma. Consider example (14) repeated below as (40).
40. go- $\beta \mathrm{a} \beta-\mathrm{a}$
'to kill by fire'
gu-ßa-w-a
'to be killed by fire'

In (40), both $[\beta]$ and [w] are [+labial]; this is a violation in Kisukuma. Thus, in this instance, / $\beta /$ is deleted instead. This current example (40) differs from the earlier example (38) in that the deleted labial sound is part of the stem, not the passive marker itself.

I have one reason why $[\mathrm{w}]$ is not deleted in (40). The deletion of the passive marker [-w-] would make it semantically hard to differentiate between the active and the passive, both active/passive forms will be [gv- $\beta \mathrm{a} \beta$-a]. In contrast, by the deletion of $[\beta]$ and keeping the passive [-w-], it would be helpful for native speakers to avoid the illegitimate $[+ \text { labial }]^{\wedge}[+$ labial] combination and also to differentiate semantically and morphologically between the active form [g $\mho-$ $\beta \mathrm{a} \beta-\mathrm{a}]$ 'to sacrifice' and the passive voice $[\mathrm{g} v-\beta \mathrm{a}-\mathrm{w}-\mathrm{a}]$ 'to be sacrificed'.

Since spirantization in examples (35) through (37) gives a semantic content of passive voice, [-w-] can be then deleted to avoid the illegitimate [+labial]^[+labial] combination, i.e. compare [gひ-taamb-a] 'to sacrifice' vs. [gv-taamva] 'to be sacrificed'.

To sum up, we have two occasions to deal with the deletion of [+labial]. In some cases, spirantization affects the preceding consonant and then $/ \mathrm{w} /$ is deleted. In other cases, spirantization cannot affect the preceding consonant; thus the preceding [+labial] consonant (such as $/ \beta /$ ) is deleted and $/ \mathrm{w} /$ is kept.

Interesting enough, the rule-based derivational theory presented by Chomsky and Halle (1968) will struggle to account for how Kisukuma chooses which [+labial] consonant to be deleted. The choice of the deletion of either [+labial] consonant $[\beta]$ or the glide [-w-] is unpredictable, albeit it is governed semantically. According to Chomsky and Halle's theory, two rules should be presented. Rule (41) is effective for example (38) and rule (42) for example (40):
41. $\mathrm{w} \rightarrow \varnothing /[+$ labial $] \ldots$ a
(for example 38)
42. C $\rightarrow \varnothing / \_$w $\quad$ (for example 40)

[+labial] [+labial]

Although the rules above seems acceptable to some extent, future work should investigate how to govern the deletion process in Kisukuma.

\section{CONCLUSION}

In this paper, I show that Kisukuma does not allow three occurrences: (i) diphthong formation, (ii) gemination, and (iii) $[+ \text { labial }]^{\wedge}[+$ labial $]$ combination. I propose that the underlying marker of passive is /-u-/, yet this marker gets glidized to avoid diphthong formation. For the marker [-iw-], I propose that it is still [-w-], yet [i] is inserted before $/ \int$, c, $\mathrm{n}$, and $\mathrm{J} /$ which are [+coronal -anterior +distributed].

Since $/ \mathrm{l} /$ and $/ \mathrm{w} /$ are not [+coronal -anterior +distributed], the left examples [g $-\mathrm{gw}$-iw-a] 'to be drunk' and [gv-l-iwa] 'to be eaten' are separately motivated. For [go-nw-iw-a] 'to be drunk', I propose that [i] is inserted to avoid the formation of geminates. For [go-l-iw-a] 'to be eaten', I propose that [i] is not inserted but it is part of the stem. Thus, the right morphological form is [gv-li-w-a] not [gv-l-iw-a] given that the active form is [gv-lj-a] where /i/ changes into [j] to avoid the diphthong formation.

For the examples such as [go-sIImv-a] 'to be dug', I still maintain that the underlying marker is the super high vowel /-u-/ which causes spirantization $([\mathrm{b}] \rightarrow[\mathrm{v}])$. Glidization and dentalization $([\mathrm{m}] \rightarrow[\mathrm{m}])$ occurs in a free order. Later, 
the [+labial] sound [-w-] is deleted because of its adjacency to the labial [v], which is an illegitimate combination in Kisukuma. After deletion, the semantic content of passive can be still derived from the spirantization and dentalization effect.

The illegitimate [+labial $]^{\wedge}[+$ labial] combination can be also seen in the last example [go- $\beta \mathrm{a} \beta-\mathrm{w}-\mathrm{a}]$ 'to kill by fire' vs. [gu- $\beta \mathrm{a}-\mathrm{w}-\mathrm{a}]$ 'to be killed by fire'. I propose that the deletion targets [ $\beta$ ] because [-w-] retains the sense of passivation.

The solution of deleting one [+labial] sound (whether the final consonant in the stem as in [gv- $\beta$ a $\beta$-w-a] 'to be killed by fire' or the passive marker itself as in [gひ-simmv-w-a] 'to be dug' raises difficulties, and I solve them via two rules triggered on semantic grounds. I recommend that future work should be done in this regard.

\section{ACKNOWLEDGMENT}

I am indebted to Dr. Masangu Matondo, a native speaker of Kisukuma, who provided me with a neat list of the data and guided me throughout the analysis with his unwavering support and constructive feedback.

\section{REFERENCES}

[1] Bhat, D.N.S. (1978). A general study of palatalization. Universals of Human Language, Greenberg ed., 47-92

[2] Chomsky, N. \& M. Halle. (1968). The sound pattern of English. New York: Harper and Row.

[3] Fleisch, A. (2005). Agent phrases in Bantu passives. In Studies in African Linguistic typology, ed. by F. K. Erhard Voeltz. Amsterdam: John Benjamins, 93-111.

[4] Matondo, M. (2006). Tonal transfer in Kisukuma. Selected Proceedings of the 35th Annual Conference on African Linguistics, ed. John Mugane et al., 125-135.

[5] Pulleyblank, D. (2006). Minimizing UG: Constraints upon constraints. Proceedings of the 25th West Coast Conference on Formal Linguistics, ed. Donald Baumer, David Montero, and Michael Scanlon, 15-39.

Muteb A. Alqarni is an assistant professor at the Faulty of Languages and Translation at King Khalid University, Abha, Saudi Arabia. He has received his MA in Linguistics (Phonetics/Phonology) from Ball State University (Indiana/Muncie, 2011) and his $\mathrm{PhD}$ in Linguistics (Morphology/Syntax) from University of Florida (Florida/Gainesville, 2015). 